\title{
HISTÓRIA DA EDUCAÇÃO DA CRIANÇA PELA FAMÍLIA NO SÉCULO 19: FONTES PARA UMA ESCRITA
}

\author{
Juarez José Tuchinski dos Anjos \\ Universidade Federal do Paraná, Brasil.
}

$\cos 80$

\begin{abstract}
Resumo
O artigo tem por objetivo, em forma de reflexão teórica e metodológica, propor, problematizar e categorizar um corpus documental para uma escrita da história da educação da criança pela família no século 19, tomando por base empírica documentação existente na maioria das regiões brasileiras, mas exemplificando-a e caracterizando-a a partir da realidade paranaense.

Palavras-chave: história da educação, criança, família, século 19, fontes.

\section{HISTORY OF CHILDHOOD EDUCATION BY THE FAMILY IN THE $19^{\text {th }}$ CENTURY: SOURCES FOR A WRITING}

Abstract

In the form of methodological and theoretical reflection, this article aims to propose, discuss and categorize a documental corpus for a writing of the history of childhood education by the family in the $19^{\text {th }}$ century, empirically based on an existing documentation for most regions of Brazil, however exemplifying and characterizing it from the reality in the State of Paraná.

Key-words: history of education, child, family, $19^{\text {th }}$ century, sources.

\section{HISTORIA DE LA EDUCACIÓN DEL NIÑO POR LA FAMILIA EN EL SIGLO 19: FUENTES PARA UNA ESCRITA}

\footnotetext{
Resumen

El artículo tiene como objetivo, en forma de reflexión teórica y metodológica, proponer, problematizar y categorizar un corpus de documentos para una escrita de la historia de la educación del niño por la familia en el siglo 19, teniendo por base empírica una documentación existente para la mayoría de las regiones brasileñas, pero ejemplificándola y caracterizándola a partir de la realidad paranaense.

Palabras-clave: historia de la educación, niño, familia, siglo 19, fuentes.
} 


\section{HISTOIRE DE L'EDUCATION DE L'ENFANT PAR LA FAMILLE AU $19^{\mathrm{e}}$ SIECLE: SOURCES POUR UNE ECRITURE}

\section{Résumé}

L'article vise, sous la forme de réflexion théorique et méthodologique, proposer, problématiser et catégoriser un corpus documentaire pour une écriture de l'histoire de l'éducation de l'enfante par la familie au $19 \mathrm{e}$ siècle, prenant par base empirique une documentation existante pour la plupart des régions du Brésil, mais l'ilustrant et l'caracterisant à partir de la réalité paranaense.

Mots-clé: histoire de l'education, enfant, familie, $19^{\mathrm{e}}$ siècle, sources. 


\section{Introdução}

A educação da criança pela família no Paraná do século 19, mais $\triangle$ especificamente entre os anos de 1853 a 1889, é o objeto de uma pesquisa de doutorado em andamento. Com a expressão educação da criança pela família tenho nomeado aquela educação não escolar, caracterizada pela transmissão de hábitos, comportamentos e condutas à criança, com vistas a sua inserção na família e na sociedade, forma educativa muito anterior à escola e com a qual esta convive ainda hoje ${ }^{1}$.

O desenvolvimento desta pesquisa colocou-me diante do problema das fontes das quais poderia servir-me para a produção de minhas interpretações. Após o percurso pelos arquivos paranaenses, percebi que a variada documentação disponível poderia dizer muito a respeito desse fenômeno educativo no âmbito da família, não apenas para minha investigação, mas também para outras que, eventualmente, desejem ocupar-se deste objeto pouco visitado na história da educação brasileira ${ }^{2}$ e que, por essa razão, merece ser considerado, em especial se levarmos em conta que para a maior parte dos brasileiros que viveram no século 19 esse pode ter sido o único o espaço de formação que conheceram na infância, de modo que só será possível um conhecimento cada vez mais consistente da educação naquele período quando essa faceta da história for também visitada.

Diante disso, o objetivo neste trabalho é, em forma de reflexão teórica e metodológica, propor, problematizar e categorizar um corpus documental para uma escrita da história da educação da criança pela família no século 19, tomando por base uma documentação existente na maioria das regiões brasileiras, mas exemplificando-a e caracterizando-a a partir da realidade paranaense.

Ainda que em matéria de produção de evidências permaneça válido o alerta de Lucien Febvre (1989) de que essa etapa é também elemento próprio do ofício do historiador, que precisa ser empreendida por ele para cada pesquisa que se propõe a realizar, não se deve desconsiderar, por outro lado, que o conhecimento histórico avança não apenas individualmente, mas, sobretudo, como expressão de um esforço coletivo em compreender e fazer compreender (Febvre, 2009), de modo que as reflexões efetuadas na solidão da oficina podem e devem ser compartilhadas com os demais praticantes do ofício, tanto para que se proceda à sua crítica, quanto para melhor compreender as experiências educativas do passado, em suas múltiplas formas e configurações.

A princípio a escrita da história da educação da criança pela família esbarra nas mesmas limitações encontradas pelos historiadores da família, muito bem resumidas por Edward Shorter, para quem

\footnotetext{
1 Julguei que denominá-la educação informal, como é corrente na pedagogia para referir-se a esse tipo de educação, seria anacrônico para o século 19, donde o empenho por produzir uma definição consoante com o que tenho percebido ser essa experiência histórica no período analisado. Cumpre explicar ainda que utilizo a preposição pela com o intuito de evidenciar a família não apenas como locus educativo, mas, sobretudo, como agente histórico, produtora de fenômenos educativos voltados à criança. Essa família de que falo possui ainda rosto e forma bem definidas: é aquela composta pela mãe, pai e filhos, vivendo em uma mesma residência, ou seja, a chamada família nuclear moderna.

2 Sobre essa lacuna na produção, vide, por exemplo, os levantamentos efetuados por Bastos (2006, p. 15); Monarcha (2007, p. 74); Faria Filho (2008, p. 95); Gondra; Schueler (2008, p. 291) e Galvão; Lopes (2010,
} p. 19). 
a dificuldade de escrever uma história da família está em as principais personagens, os milhões de homens e mulheres anônimos que popularam o mundo do cotidiano, não falarem. Ao contrário das loquazes esposas dos aristocratas e dos romancistas da parisiense Rua de Saint-Honoré, em que os historiadores sociais tanto se apoiam, essas pessoas não passaram os seus pensamentos mais íntimos para o papel. Nem se mostravam muito comunicativos com os observadores literatos no tocante às periferias do seu mundo. Quanto ao que sentiam, guardavam um silêncio tumular, mesmo com os cônjuges e os filhos, já para não falar em preservar um registro para a posteridade. Mas o âmago da história da família é precisamente esta crônica dos sentimentos. (Shorter, 1995, 14)

Embora o quadro geral seja, para o século 19 brasileiro, basicamente o mesmo desenhado por Edward Shorter em relação à Europa moderna, em que na maioria das vezes os principais personagens não falam, senão, por meio de evidências indiretas, sabemos que na pesquisa histórica é preciso um pouco de coragem, paciência e criatividade para superar os interditos impostos pela ação do tempo e do homem sobre a documentação disponível. No geral o trabalho de garimpagem nos arquivos sabe compensar a quem neles se atira, mas nem todo o prazer esconde o fato de que aquilo que se encontra, num primeiro momento, não passa de material bruto, como o designava Georges Duby, uma "massa inerte, o enorme amontoado de palavras escritas mal extraídas das pedreiras de onde os historiadores se abastecem, selecionando, recortando, ajustando, para construir em seguida o edifício cujo projeto conceberam provisoriamente" (Duby, 1993, p. 21).

A essa massa inerte cabe ao historiador restituir-lhe a vida, não a vida do papel ou dos escritos que sempre serão inanimados, mas a vida daqueles que no turbilhão de suas existências, ora em tempos de tranquilidade, ora em tempos de agitação; às vezes em meio a viagens e passeios, outras em circunstâncias trágicas; com frequência no cumprimento de um trabalho ou de uma função desempenhada, seja na sociedade, seja na intimidade do lar, produziram esse material ou foram produzidos a partir dele e, por terem-no tocado, dado forma e existência, permitem que ali se apreenda alguma coisa às vezes muita, com frequência muito pouca, das suas vidas e suas relações, de modo especial com a criança, não na pretensão de que conseguiremos tudo saber e conhecer, mas de tentarmos, com empenho, rigor e honestidade, "reencontrar o sabor do passado, a vida, os sentimentos, as mentalidades de homens e de mulheres, mas em sistemas de exposições e interpretações de historiadores do presente" (Le Goff, 2007, p. 103).

É nesse esforço de explicação que o historiador aprende a ouvir aqueles que falam, mas também aqueles de quem se fala e que podem ter, ainda que de forma indireta, parte de suas falas recuperadas ou, ao menos, consideradas. Desse modo, todas as famílias das quais nos chega algum tipo de evidência podem, em alguma medida, mesmo que com diferentes níveis de precisão, ter suas experiências educativas identificadas, narradas e interpretadas pelo historiador.

Do contato com a variedade de documentação existente nos acervos paranaenses, arquivos públicos e bibliotecas, foi possível observar que a família comparecia nela de diversas maneiras: às vezes, como produtora das fontes, menos frequente; outras, produzida por elas, situação singular, mas bem documentada, e, no restante das vezes, posta em relação com inúmeras outras dimensões da experiência social daquele tempo, 
sendo que, em todos os casos, de múltiplas formas, era possível capturar sua presença. Ao mesmo tempo em que interrogava esses documentos um a um dediquei-me à reflexão sobre as possibilidades de explicações que ajudariam a construir, observando que uma crítica dos diferentes lugares de sua produção, lugar que como lembra Certeau (2002) permite algumas coisas, proíbe e torna possível outras, seria de grande auxílio para melhor compreender as maneiras pelas quais as evidências do passado das famílias se tornariam testemunhas sobre elas, passíveis de serem indagadas. Ao fim desse exercício cheguei a uma tripla categorização que, sem pretensão de esgotar o horizonte de análise, permitiu uma aproximação um pouco mais segura das experiências da educação dada pela família, à criança, no século 19.

\section{Fontes produzidas pela família}

A primeira categoria a que cheguei é a da documentação produzida pela família, composta por correspondências, memórias, autobiografias, diários e entrevistas.

As correspondências localizadas, no caso paranaense, são constituídas pelo monumental acervo pessoal do presidente da Província Jesuíno Marcondes de Oliveira e Sá, que abarcam mais de sessenta anos, não só da sua vida, mas da vida de sua família; as correspondências pessoais e de negócios de David dos Santos Pacheco, o barão dos Campos Gerais e algumas cartas escritas por William Michaud, imigrante suíço que viveu no litoral paranaense e que, além de pintor, foi professor de primeiras letras. Delas, emergem constantes referências ao cotidiano da criança e sua formação, bem como situações nas quais os pais agem, ora com rigor, ora com mansidão, na busca da transmissão de hábitos e comportamentos a seus filhos no tempo da infância.

Documentação escassa, mas existente em várias regiões brasileiras, as cartas particulares, enquanto documentos históricos possuem uma vantagem e um limite intrínsecos: são feitas para ocultar, tanto quanto para revelar (Perrot, 2009), ou seja, não devem dar a ilusão de acesso a uma realidade nua e crua, mas, antes, a uma realidade interpretada, assumida, negada, ocultada, manipulada, que queria ser dada a ver pelo remetente ao seu destinatário. Ainda assim, lembra-nos Michelle Perrot, elas nos levam, pelo menos, "à entrada da Fortaleza" (Perrot, 2009) que é o mundo da família. Sem dúvida, elas permitem adentrar na sua intimidade, onde dá-se efetivamente o cotidiano da educação da criança e suas relações com os adultos que a rodeiam.

As memórias e autobiografias de infância que localizei nos acervos paranaenses, num total de 21 textos de diferentes extensões e estilos de escrita, trazem à cena imigrantes, políticos, médicos, literatos, professores e donas de casa entre aqueles que procuraram transportar para o papel lembranças e reminiscências do seu passado e da sua infância, período no qual são localizáveis experiências educativas vivenciadas na família no século 19. Esse gênero, felizmente, é mais facilmente localizável que as cartas, especialmente em bibliotecas, uma vez que, frequentemente, tais relatos foram transformados em livros. Um instrumento de pesquisa interessante para esse tipo de busca são os dicionários bibliográficos, como, por exemplo, aquele organizado por Júlio Estrella Moreira (1957), abarcando a produção paranaense de 1857 a 1957. Deve-se observar que esse tipo de documentação do ego foi, geralmente, produzido e impresso no século 20 , mas por terem seus atores nascido no século anterior, torna-se evidência para 
pensar os processos de sua educação nesse período, desde que neles, obviamente, recordem suas infâncias.

Tanto os livros de memórias, quanto as autobiografias são produção memorialística, sendo fundamental considerar a função social dessa memória, amplamente salientada por Peter Burke (2000): ela serve, tanto para lembrar, quanto para esquecer, erigir heróis e acontecimentos sobre os quais o historiador precisa aprender a identificar e separar o concreto do fabricado, sob pena de nada compreender. Certamente pode-se referir níveis de veracidade nestes relatos: mais importante que as aventuras vivenciadas por seus autores na infância, repletas de emoção ou altruísmos e por isso mesmo mais suscetíveis a exageros, estão os contextos e situações nas quais elas deram-se e que por poderem ser contrastados com outros testemunhos, nos oferecem um grau de assertividade maior do que se fossem tomadas apenas per si. O valor desses testemunhos é que permitem, não obstante as obliterações próprias da memória, tentar ouvir as experiências de educação vividas pela própria criança, ainda que evocadas por ela na vida adulta, naquilo que Egle Becchi (1994) denominou retórica da infância: a criança do passado falando pelas mãos de outro, o adulto.

Outro tipo de documentação encontrada e bastante rara, como lembra Evaldo Cabral de Mello (1997, p. 386), são os diários pessoais, no caso paranaense, em sua maioria, fragmentos manuscritos, mais um tipo de memória. Esta, porém, recolhida diariamente pelos seus autores, numa tentativa de inventariar o cotidiano. Neles o autor opera também uma seleção entre o que era digno de nota e aquilo de que se abria mão de registro: os diários, lembra Colin Heywood, são por essa razão testemunhos inevitavelmente autocensurados (Heywood, 2004, p. 15), mas que ainda assim remetem ao cotidiano familiar e no cruzamento com outros testemunhos, mostram-se bastante reveladores. A título de exemplo, num dos diários pertencente ao português Antonio Vieira dos Santos, que viveu no Paraná na primeira metade do século 19 , encontram-se registradas as datas de nascimento, doenças e principais eventos da vida de seus filhos e dos filhos de seus escravos, inclusive alguns momentos de desentendimentos com eles, onde se percebe, apesar da autocensura desse tipo de empiria, evidências dos valores, hábitos, comportamentos e tensões vivenciadas na sua transmissão no ambiente familiar. Nele se captura o quanto a ternura e o afeto também marcavam as relações dos pais com os filhos. Ainda a respeito desse tipo de documentação, não se deve esquecer que existem casos em que os diários pessoais também foram transformados em livros, valendo a pena empenhar-se por sua localização em bibliotecas e sebos.

Entrevistas feitas com pessoas que nasceram e viveram a infância no século 19 são raras, mas existem e constituem-se num testemunho possível de ser investigado, especialmente nos acervos dos chamados museus da imagem e do som que, frequentemente, em função de projetos institucionais realizados no período da ditadura, ao menos no caso paranaense, realizavam gravações em áudio com personalidades nas décadas de 1960 a 1980, com vistas à produção de uma memória nacional e regional. Com um pouco de sorte pode-se encontrar registros relevantes sobre o Brasil Imperial.

No Paraná localizei as entrevistas concedidas pelo maestro Bento Mossurunga e dona Francisca Batista de Carvalho, nascidos em 1877 e 1895, respectivamente. Nessas gravações magnéticas, cuja tecnologia pôde alcançar os depoentes, ambos são interpelados a respeito de suas vidas e feitos, mas também sobre suas experiências 
infantis em suas cidades de origem, no caso Castro e Ponta Grossa, e as relações mantidas com os seus pais, irmãos e outras crianças. O material exige uma demorada transcrição, tornada mais difícil pela idade e tom de voz dos entrevistados e às vezes pela própria inabilidade dos entrevistadores, nem sempre pacientes para deixar suas testemunhas falarem, interrompendo-as a todo tempo. Nesses casos bastante particulares estamos diante de uma inusitada fonte oral, arquivos provocados, como os designou Jacques Ozouf (1973), sobre os quais o entrevistador - nem sempre historiador age como aquele que força as testemunhas a falarem e a recordarem, mas num jogo em que as resistências são tão ou mais intensas do que aquele com documentos escritos e as negociações fortes o bastante para agir muito particularmente sobre espaço de interrogação do entrevistador. É nos interstícios do perguntado, do dito, do não dito e do como foi dito que emergem informações que talvez jamais fossem obtidas em outros testemunhos, donde a importância do uso também deste delicado tipo de documentação para a escrita da história da educação da criança pela família.

\section{Fontes produzidas sobre a família}

A segunda categoria que quero problematizar, composta por um único e complexo conjunto de documentos, é o daqueles produzidos sobre a família, dos quais emergem fragmentos da educação e do educar. Trata-se de peças criminais e judiciais envolvendo crianças e suas famílias, que podem ser encontrados nos arquivos judiciários, embora no Paraná a documentação por mim utilizada esteja custodiada no Arquivo Público Municipal Casa da Memória da Lapa.

Ao interrogar esse tipo de documentação com a intenção de apreender o cotidiano das famílias, a exemplo do que fez Emmanuel Le Roy Ladurie (1975) ao investigar a vida dos camponeses de Montaillou, deve-se procurar compreender não tanto o que motivou a produção deste material, embora isso também ocorra, mas, sobretudo, as vidas "apaixonantes de seus envolvidos" (Le Roy Ladurie, 1975, p. 10), desde que se tomem os acidentes, mortes e catástrofes que impuseram a abertura de tais processos, com o necessário respeito pelas pessoas sobre as quais certos sofrimentos se abateram no passado, como espaço de inestimáveis possibilidades para o historiador (Le Roy Ladurie, 1975).

O arquivo que guarda tais evidências, afirma Arlette Farge (2009), é um vestígio bruto que desvenda o que jamais seria revelado de outra forma, porque dá acesso ao não dito, à revelia de quem fala (Farge, 2009). Ele se constitui numa brecha no tecido dos dias, por onde se podem entrever, em meio a situações de violência e sofrimento, o cotidiano das pessoas envolvidas, suas relações sociais (Farge, 2009). Assim, ao observar nos gabinetes da polícia ou nos tribunais algumas famílias que dão explicações sobre as situações que culminaram nas tragédias sobre as quais depõem ou são interrogadas, pode-se chegar a fragmentos de suas vidas ordinárias, nas quais, por uma fatalidade, a harmonia do dia a dia foi abalada. Ao pôr a atenção em situações que, declaradamente, envolveram crianças torna-se possível fazer emergir os contextos educativos por elas experimentados no interior de suas casas e que por ação de integrantes da própria família ou de agentes externos foram modificados, abalados, interrompidos. Se as palavras ditas dão acesso às moradas da história (Farge, 1999), a 
articulação do que desaparece sobre o que aparece (Farge, 1999) poderá dar acesso à algumas experiências de educação da criança vividas nas famílias.

O quadro n. 1 apresenta a descrição do conjunto das peças documentais localizadas na Lapa entre os anos de 1871-1896, período escolhido para o trabalho naquele acervo pela legibilidade da documentação e acesso, embora os processos ali existentes abarquem um arco de tempo muito maior, do século 18 ao 20, com uma descrição tipológica, realizada com base na leitura prévia de parte da documentação, bem como na categorização utilizada pelas Oficinas do Poder Judiciário do Arquivo Público do Paraná, onde se trabalha, há alguns anos, com materiais muito semelhantes aos da Lapa. As lacunas no quadro são, no momento, também lacunas no meu conhecimento acerca dessa empiria.

\section{Quadro 1}

Descrição das peças do Arquivo Judicial existentes na Casa da Memória da Lapa (1871-1896).

\begin{tabular}{|c|l|l|}
\hline Quantidade & \multicolumn{1}{|c|}{ Título oficial } & \multicolumn{1}{c|}{ Descrição } \\
\hline 1 & Ação de liberdade & $\begin{array}{l}\text { Ação para libertação de ingênuos, com } \\
\text { interrogatórios. }\end{array}$ \\
\hline 1 & Apelação crime & $\begin{array}{l}\text { Julgamento em segunda instância, com } \\
\text { interrogatórios. }\end{array}$ \\
\hline 1 & Auto de admoestação & \\
\hline 1 & Auto de divisão de terrenos & Partilha de bens, no caso, envolvendo crianças. \\
\hline 1 & Auto de Perguntas & Interrogatório policial. \\
\hline 14 & Auto de quitação & Pagamento de dívidas envolvendo crianças. \\
\hline 6 & Corpo de delito & $\begin{array}{l}\text { Análise feita por legista em cadáveres de crianças, } \\
\text { com descrição dos crimes e circunstâncias da morte. }\end{array}$ \\
\hline 1 & Inquérito policial & $\begin{array}{l}\text { Denúncia recebida pela autoridade policial, com } \\
\text { interrogatórios. }\end{array}$ \\
\hline 1 & Indagação policial & $\begin{array}{l}\text { Denúncia recebida pela autoridade policial, com } \\
\text { interrogatórios. }\end{array}$ \\
\hline 1 & Insinuação & Termo de doação de bens para criança. \\
\hline 1 & Requerimento & Processo e julgamento em 1 ${ }^{a}$ instância. \\
\hline 6 & Sumário crime & Pedido feito à autoridade policial. \\
\hline 2 & Sumário culpa & Processo judicial abreviado, com testemunhas. \\
\hline 1 & Termo de bem viver & $\begin{array}{l}\text { Denúncia recebida pela autoridade policial, com } \\
\text { interrogatórios. }\end{array}$ \\
\hline 3 & Tribunal do júri & $\begin{array}{l}\text { Julgamento realizado por juiz e jurados, com } \\
\text { interrogatórios. }\end{array}$ \\
\hline
\end{tabular}

Fonte: Arquivo Público Casa da Memória da Lapa.

Mais do que conhecer a denominação e a tipologia, é oportuno problematizar a natureza destes 42 documentos, que variam de 20 a 200 páginas cada um. De modo geral, a partir das constatações dos pesquisadores do Arquivo Público do Paraná em relação a material similar por eles analisado e certamente válidas para esse tipo de 
documentação em outras regiões brasileiras, um crime, ao ser investigado pelas autoridades, passava por três fases no século 19. A primeira é a do conhecimento ou investigação, feita pela autoridade policial, seguindo o método inquisitivo, com perguntas que almejam a verdade dos fatos. (Portella et al, 2006). Dessa fase, em que não há possibilidade de defesa, constam dez documentos no Arquivo Judiciário da Lapa: autos de perguntas, inquérito policial, indagação policial e sumário de culpa.

Creio que aqui também poderiam ser incluídos os exames de corpo de delito, uma vez que deles podiam decorrer a comprovação de crimes e eram feitos por ordem da autoridade policial. No caso, outros 14 documentos. Nessa fase, lembram ainda Portella et al, "esses processos administrativos não chegam a transformar-se em processos judiciais, portanto, não existindo análise de mérito pelo juiz competente" (Portella et al., 2006, p. 5). Quando a autoridade decidia pelo indiciamento do acusado, tinha lugar a segunda fase, a do processo, no qual constam, tanto a documentação da investigação, quanto testemunhos diversos, na estrutura de um julgamento, seguindo o princípio dispositivo "permitindo às partes apresentarem suas provas e defesas". (Portella et al, 2006, p. 5) Foram encontrados para a Lapa dez documentos: processo crime, sumário crime e tribunal do júri. A última fase era a da apelação, com um único documento localizado na Lapa: apelação crime. No momento, sete documentos ainda permanecem sem uma classificação, que está sendo buscada no desdobramento da pesquisa.

Chamar a atenção para a natureza de tais evidências, além de ajudar a compreender a lógica que as produz, aponta pistas importantes para a crítica documental. Nelas os integrantes das famílias acusam, mentem, explicam, falam. Mas esses relatos foram fixados no tempo por outras pessoas, como registros escritos de produções orais (Ginzburg, 1991), lembrando que o ato de falar numa situação atípica - tensão, dor, medo - deve ser levado em conta na elaboração das interpretações históricas que o tomam por base, já que seu conteúdo nos chega pela curiosidade daqueles que interrogam, num poderoso enquadramento sob pressão ${ }^{3}$ (Ginzburg, 2001), no qual suas perguntas não eram as nossas, sendo que tal enquadramento precisa ser enfrentado e rompido para permitir aparecer o não dito, que responde às questões colocadas pelo historiador. Por outro lado, essas falas vêm carregadas da criatividade dos bons contadores de história (Davis, 2001), que, mesmo ao construírem versões falsas ou distorcidas dos eventos que relatam, deixam entrever os padrões socialmente aceitos ou as irregularidades condenadas, por exemplo e naquilo que mais interessa, em termos de educação e da vida que pais proporcionavam a seus filhos e filhas.

Acontecimentos pontuais, na ótica de Le Roy Ladurie (2002), contém em si a possibilidade de iluminar e refletir as culturas e conflitos de uma época, mas também de grupos neles envolvidos. Esses acontecimentos, na vida das famílias da Lapa, são os eventos que as fizeram comparecer diante da polícia ou de um tribunal: morte acidental $(9)^{4}$, estupro (9), transmissão de bens (4), ferimentos (4), brigas (3), Rapto (2), incesto (2), fratricídio (2), desentendimentos verbais (2), maus-tratos (1), tutela de ingênuos (1),

\footnotetext{
${ }^{3} \mathrm{O}$ enquadramento sob pressão consiste em levar o interrogado a comprar a visão explicativa do interrogador, algo verificado por Carlo Ginzburg em relação ao benandanti que de bruxos bons que lutavam pela fertilidade dos campos, após cinquenta anos de perseguição e interrogatórios, assumiram a identidade a eles atribuída pelos inquisidores, a de feiticeiros.

${ }^{4} \mathrm{O}$ número entre parênteses se refere à quantidade de processos sobre um mesmo tipo de acontecimento. Hist. Educ. (Online) Porto Alegre v. 19 n. 45 Jan./abr., 2015 p. $67-83$
} 
infanticídio (1), gravidez de menor (1), assassinato (1). Cada um desses acontecimentos constitui-se num complexo observatório do social (Farge, 1999) que permite apreender as etapas de socialização da criança, entrada na vida sexual, relações de tensão entre pais e filhos, os limites entre a violência que educa e aquela que maltrata, as responsabilidades de adultos para com a infância, as relações entre crianças de diferentes famílias, com plurais itinerários educativos, a criança na sua relação com a morte, dentre outros.

Robert Darnton (2005), contudo, faz um alerta sobre a tendência dos historiadores em servirem-se de narrativas sobre incidentes, como as que emergem dos arquivos policiais, para a produção de explicações históricas. Segundo ele esses relatos em si já são boas histórias e podem, ao final, resumirem-se apenas em boas narrativas e não em boa bagagem de conhecimento histórico. Um caminho para contornar esse risco é realizar a concatenação dos eventos, no esforço de encontrar seu significado: "o que eles significavam para as pessoas que os vivenciaram" (Darnton, 2005, p. 303). Percebi um limite fundamental nesse tipo de documentação, com o qual venho aprendendo a lidar. No início de minhas pesquisas, pensava poder servir-me desta documentação para compreender a educação da criança. Ledo engano. Ela, definitivamente, não serve como porta de entrada para um objeto tão complexo, justamente porque as motivações que deram lugar a tais processos nasciam de preocupações as mais variadas, como a salvaguarda da honra paterna ou o simples desejo de fazer justiça contra aqueles que ousaram opor-se à ordem que se buscava estabelecer no Império. Esse, inclusive, é o significado mais evidente para a grande maioria dos homens e mulheres que vivenciaram e foram atores deste processo.

Mas "jogar a criança fora com a água da bacia" (Ginzburg, 2006, p. 16) também não é solução sensata para os dilemas da pesquisa histórica. Se não serve de entrada, a documentação tem se revelado importante para preencher lacunas, funcionando como janela pela qual se consegue enxergar, por meio do contraste com outros documentos, cenas do cotidiano das crianças que não era intenção de seus pais narrar ao serem convocados para prestar depoimentos e que, na maioria das vezes, pouca importância tinha até mesmo para os interrogadores, mas que agora, num contexto de pesquisa em que justamente esse cotidiano é que é esclarecedor para o problema posto pelo historiador, promove a compreensão da educação dada à criança pelas famílias.

\section{Fontes produzidas nas relações com a família}

A terceira categoria, e mais abundante, é a da documentação produzida nas relações com a família, isto é, produzidas por atores e instituições que travavam contato direto ou indireto com o mundo da família ou com as quais a própria família estabeleceu relações, sobretudo, quando foram exaradas por aquelas instituições que alimentavam expectativas em torno da educação que devia ser dada a criança pelo pai e pela mãe. ${ }^{5}$

Um primeiro grupo privilegiado é a documentação oficial produzida pelos governos imperial, provincial e local: discursos, relatórios, correspondências de governo e, particularmente, a legislação e as posturas municipais. É bem verdade que não manifestam, a princípio, preocupação intensa com a educação da criança pela família,

\footnotetext{
${ }^{5}$ Uma das hipóteses de minha tese é de que, no Paraná, tais instituições eram a Igreja, a imprensa e o Estado Imperial, também representado pelas autoridades provinciais e municipais. 
mas o seu silêncio que é revelador, pois, embora não formule com clareza suas expectativas, os agentes do governo as produzem de modo concreto em forma de leis e normas que visavam a regular o comportamento da sociedade.

Se essa relação já foi apontada por Jacques Donzelot (1980), permanece pouco estudada no seu caráter educativo, ou seja, formador de comportamentos e condutas a partir da ação esperada e com frequência imposta à família nas situações que envolviam as relações com a criança. Devido a essa ação por meio da lei, também alguns tratados de Direito Civil, lembrando que durante o Império não existia um código civil e nessa matéria o que vigorou foram as determinações do Código Filipino, em especial o livro V, bem como as Leis Extravagantes do Reino de Portugal, e Direito Criminal contendo as interpretações dos bacharéis-políticos, dão testemunho de como essas relações, ordenadas por prescrições legais, visavam a impor à família determinados padrões de comportamento a serem inculcados na criança. Embora seja documentação de ordem prescritiva, aponta a direção para a qual se queria que a sociedade brasileira caminhasse, fornecendo-nos um horizonte para pensar como a família se portava diante desse tipo de expectativa enunciada em forma de ordenamento social.

Um segundo grupo de evidências é o contido na documentação eclesiástica, bastante variada: encíclicas papais, que tratam de temas mais gerais, abrangendo, principalmente, a realidade europeia, mas cujo conteúdo era apropriado pelos bispos para a realidade brasileira; cartas pastorais dos bispos responsáveis pelo governo das dioceses, nas quais tratavam de problemas específicos de seu território eclesiástico; os Compromissos de Irmandades, relação dos direitos e deveres aos quais os integrantes de uma associação religiosa ficavam sujeitos, prevendo comportamentos esperados destes e permitindo, em alguns casos, a presença de crianças nas confrarias; os tratados de espiritualidade e moral, livros de devoção com prescrições morais, alguns muito antigos como a Introdução à vida devota de São Francisco de Sales, século 16, outros produzidos especificamente por bispos brasileiros século 19 como O livro da família, de 1879, de autoria de dom Macedo Costa, bispo do Pará (1861-1890), e que teve larga circulação no período republicano; os catecismos, contendo representações religiosas acerca de diversos aspectos dos fenômenos sociais; os rols de desobriga, listas de famílias e seus integrantes efetuadas pelos párocos com o objetivo de acompanhar o cumprimento das obrigações religiosas da parte de seus paroquianos, individualizando adultos e crianças em cada casa bem como a frequência com que recebiam os Sacramentos, e as Constituições Primeiras do Arcebispado da Bahia, legislação eclesiástica que, ao contrário do que o nome sugere, vigorou em todas as dioceses brasileiras nos séculos 18 e 19.

Com exceção das encíclicas papais, que no Brasil foram publicadas parcialmente pela Editora Paulus na coleção Documentos pontifícios, o restante da documentação eclesiástica pode ser encontrado nos arquivos paroquiais, diocesanos e, quando impressos, em bibliotecas de antigos colégios católicos, seminários, conventos e mosteiros. No caso paranaense foi localizada nos arquivos da Paróquia Santo Antonio da Lapa e da Casa da Memória de Curitiba, que possui cópia de parte da documentação da Catedral Basílica Menor de Nossa Senhora da Luz dos Pinhais. Diferentemente da documentação oficial, ainda que em função do regime do padroado não se possa desconsiderar que, de certo modo, esta também o era, alguns bispos e papas com 
frequência manifestaram preocupação com a educação que devia ser dada pela família à criança, principalmente num contexto de implantação do ultramontanismo, em que esperava-se que a sociedade se mantivesse católica, aprendendo a obedecer primeiro ao Romano Pontífice e depois ao Imperador. E não apenas se preocupavam, como apontavam práticas e modos pelos quais essa educação, sempre mediada pela família, poderia ser realizada.

O limite desses documentos é, justamente, esse caráter prescritivo que precisa ser posto em relação com a realidade do alcance da Igreja sobre seus fiéis, dificultado, tanto pelo número insuficiente de clérigos para atender a população, quanto pelas maneiras próprias do brasileiro viver sua fé, muitas das quais se davam à margem do catolicismo oficial. Todavia, Roque Spencer Maciel de Barros recorda que "se o verdadeiro catolicismo não imperava nas consciências, dominava, contudo, nas instituições" (Barros, 1986, p. 27): no Estado, nos Códigos de Lei, nas carreiras intelectuais e políticas pela obrigação do juramento religioso bem como "na base das famílias, pela inexistência do casamento civil [...]. Se o catolicismo não apoiava seu prestígio nas consciências individuais, descansava sua força no caráter confessional das instituições civis" (Barros, 1986, p. 27). É justamente essa força institucional que confere importância também ao discurso eclesiástico sobre a educação, uma vez que em determinadas situações ou etapas da vida pode ter tido amplo impacto sobre as famílias paranaenses e brasileiras.

O terceiro grupo, que oferece múltiplas formas de testemunho, é o da imprensa periódica. De modo geral, nos trabalhos de história da educação, a imprensa é tomada como uma Entidade quase que com vida própria, uma tribuna da qual intelectuais, políticos e educadores buscam agir sobre as massas, modificando suas condutas e apontando novos rumos para o Império brasileiro. Não contesto essa interpretação, pois entendo que esse é um testemunho intencional dado pelo jornal e que deve ser destacado sempre que necessário. Mas parar por aqui seria desprezar as outras formas de testemunhos, quase sempre não intencionais, que dele também emergem.

Aquilo que Thompson (2009) demonstrou em relação à prática da venda de esposas na Inglaterra, que só pode ser devidamente estudada pelo recurso a anúncios de jornais e editais neles publicados, levando-o a produzir uma explicação para o curioso fenômeno inglês numa perspectiva de história social, é promissor também para a análise das práticas educativas da família no Brasil do século $19^{6}$. Ao longo do contato com essa documentação percebi que o jornal funciona como um grande repositório de fragmentos de vida, pelos quais pessoas anônimas deixavam escapar indícios de suas histórias familiares e modos de educar seus filhos, em registros de anúncios, em necrológios e em publicações a pedido. Por outro lado, também compareciam, à contragosto, em notícias

\footnotetext{
${ }^{6}$ Em linhas gerais, o que me chamou a atenção no trabalho do historiador britânico foi o fato de deparar-se com um fenômeno que era plenamente conhecido na cultura inglesa, causando às vezes constrangimento aos britânicos e fornecendo motivo de piadas para os seus primos franceses: a venda de esposas. Todavia, a ausência de registros sobre essa prática pouco contribuía para compreendê-la. Foi então que Thompson recorreu à anúncios e editais em jornais - fornecidos com frequência por seus colegas, confessa - conseguindo demonstrar o que aquele costume realmente significava para os casais: a possibilidade de divórcio, que não era permitido pela legislação então em vigor. Ele não se preocupou demais em tomar o jornal como uma evidência apenas da elite letrada, mas conseguiu apontar como através deles, as classes subalternas também podem ter suas vozes recuperadas e interpretadas. Tal como ele, eu também me deparava como uma prática que ninguém nega que existiu, a educação, mas da qual as evidências eram difíceis de localizar.
} 
sobre crimes, julgamentos e incidentes do cotidiano, onde, às vezes, seus modos de educar na intimidade eram expostos aos leitores do jornal. Assim, ele é testemunha plural da complexa realidade na qual estava imerso: nos ajuda a perceber tanto as expectativas da sociedade em relação à educação da criança, quanto os múltiplos modos pelos quais as práticas educativas se processavam na intimidade do lar, ainda que reveladas à contragosto de seus praticantes.

Os relatos de viajantes constituem-se noutro grupo importante de testemunhos sobre a educação da criança pela família. É preciso reconhecer que nem todos os viajantes que passaram pelo Brasil durante o século 19 registraram com detalhes o cotidiano da criança. Isso se explica em parte pelo fato de que só poderia falar do domínio privado, o viajante que se abrigou ou foi hospedado nesse espaço. Por outro lado, devido a trabalhos ou ao tipo de viagem, às vezes de exploração de estradas e rios ou verificação das condições de determinada região para receber imigrantes, por vezes tal informação era irrelevante ou até mesmo inadequada para o relato que escrevia.

No geral, sobre esse tipo de documentação, permanecem válidas as considerações de Linda Pollock: "é provável que os relatos de viajantes sejam mais descritivos de costumes reais que a literatura de orientação [manuais e tratados de educação], mas também é preciso dizer que estão prejudicados por diferenças culturais" (2004, p. 64). Assim, o viajante nos ajuda a estabelecer contato com o mundo da família e da criança, mas trata-se de um mundo que ele não apenas descreve, mas interpreta e significa por meio do seu relato, que é informado não apenas por seus olhos, mas pelas diferenças culturais do observador em relação aos nativos. É preciso, portanto, ficar atento para separar o que o viajante pode ter visto daquilo que ele quis dar a ver, cientes de que ambas as dimensões estão entrelaçadas na literatura de viagem, sendo fundamental, sempre que possível, o cruzamento de dados tanto entre diferentes relatos de viagem como dos relatos com outros tipos de testemunhos.

As imagens, pinturas e fotografias, são testemunhos aos quais também se pode recorrer nesse tipo de pesquisa. No primeiro caso deve-se ter presente que as pinturas não fixam e imortalizam uma realidade, mas produzem-na de acordo com as percepções do artista pintor. O caderno de viagem de Jean-Baptiste Debret (Bandeira, 2006), um dos mais famosos artistas itinerantes do Brasil do século 19 é prova disso: ele contém vários esboços de pessoas que eram feitos em diferentes ocasiões e lugares e que depois eram copiados e inseridos em paisagens para compor as telas, de modo que o realismo das cenas talvez estivesse mais nas pessoas individuais representadas que no conjunto da composição. Já as fotografias, cada vez mais popularizadas à medida que se avança na segunda metade do século 19, especialmente pela ação dos fotógrafos itinerantes que ofereciam seus serviços com preços diversificados, de acordo com as técnicas disponíveis e assim acessíveis a diferentes setores da população, são evidências importantes, sobretudo no gênero retrato de família.

Mas também aqui é preciso atenção, uma vez que a ocasião da fotografia era especial e exigia preparativos igualmente especiais, além de que, mesmo sendo capturada, cortada e imortalizada a partir de um momento real, a imagem nem por isso era menos produzida, fabricada, tanto no ambiente de fundo como nas posições e posturas adotadas nas poses. Em relação a essa última questão deve-se lembrar que as próprias imposições da tecnologia fotográfica então disponível obrigavam a poses 
demoradas e rígidas, transmitindo ao registro do fotógrafo uma seriedade e sisudez que não necessariamente faziam parte do cotidiano familiar. Em face dessas questões presentes na produção, tanto do registro fotográfico, quanto da pintura, essas imagens devem ser tomadas, sobretudo, como formas de representação, naquele sentido preciso apontado por Roger Chartier: "esquemas intelectuais incorporados, que criam as figuras graças às quais o presente pode adquirir sentido, o outro tornar-se inteligível e o espaço ser decifrado" (2002, p. 17).

São construções do real que expressam os sentidos e direções que se queria dar para as realidades representadas. Uma família unida, sorridente e bem vestida representada numa fotografia, com filhos obedientes e submissos a seus progenitores pode ser, por vezes, mais a expressão de um modelo de vivência familiar que era valorizado e desejado, do que uma experiência concreta. Todavia, as duas dimensões estão presentes no testemunho fotográfico e vale a pena tentar decifrá-las, pois as representações são matrizes de práticas (Chartier, 2002) e ajudam a compreender o significado de muitas das ações educativas no âmbito familiar.

O último grupo de testemunhos é formado pela literatura do século 19. Sobre os riscos e possibilidades inerentes a este tipo de documentação, Eliane Marta Teixeira Lopes (2005) e Maria Cristina Soares de Gouvêa (2007) fornecem duas indicações fundamentais: ela pode oferecer "uma chave instigante, levantar algum dado desprezado pela historiografia corrente que se vale apenas de documentos oficiais escritos como fonte" (Lopes, 2005, p. 165), mas precisa também ser cruzada e confrontada com outras empirias, sob o risco das interpretações pairarem num vazio, "desligadas do contexto histórico que sustentou a produção dos textos analisados” (Gouvêa, 2007, p. 34).

O ponto positivo, portanto, reside na capacidade de acesso ao mundo dos valores e pensamentos em circulação sobre a educação da criança no século 19, um universo mental que, por vezes escapa às evidências anteriormente mencionadas, mas presente na literatura era um dos elementos que a tornava palatável e compreensível aos leitores pois fazia-os identificarem-se com a realidade que viviam, cuja mediação ficcional lhes era oferecida para a leitura amena, um tanto íntima, no refúgio do lar, ou coletiva e em voz alta nos saraus literários que se tornavam cada vez mais populares no Império. Por outro lado, só conseguiremos capturar com rigor e sem anacronismo esse tipo de evidência que chega pela literatura se colocarmos a atenção nas situações concretas às quais remetem, cruzando tais situações a outras semelhantes, que chegam por meio de empirias mais duras ou dizendo melhor, preocupadas mais com o registro do que consideravam real que com os elementos dessa realidade vertidos em ficção e imaginação pelos escritores.

\section{Considerações finais}

Segundo Henri-Irénée Marrou,

a fecundidade do conhecimento histórico reside, sobretudo, no diálogo que institui, entre nós, entre o Outro e o Mesmo. Tornamo-nos diferentes de nossos pais o bastante para que a educação deles nos apareça, em larga medida, sob a categoria do Outro: podem ultimamente surpreender-nos nela muitas coisas que se opõe à nossa prática e às nossas aspirações. [...] A fecundidade do diálogo não exige que renunciemos, por isso, a continuarmos sendo nós mesmos: simples instrumento de cultura, ele 
alarga nossa perspectiva, despoja o moderno dessa ingênua suficiência que o impedia de imaginar que se tenha podido ser diferente dele. Entretanto, se nos leva a refletir, não nos leva necessariamente a infletir nossa ação: o exemplo que a história nos propõe obriga-nos unicamente a verificar a solidez e a pertinência de nossas opções e tornar nossa vontade consciente de si mesma. (Marrou, 1971, p. 5)

A experiência de pesquisa nos arquivos paranaenses tem confirmado, como procurei demonstrar ao longo deste artigo, as inúmeras possibilidades empíricas para a escrita da história da educação da criança pela família no século 19. Investigar esse terreno quase inexplorado é mais uma das oportunidades para travarmos o contato entre o outro e o mesmo, ao qual se refere Marrou, isto é, a educação dada no passado à criança da qual nós, enquanto crianças, num passado mais ou menos recente, também participamos no interior de nossas famílias.

Talvez, ao nos lançarmos a esta tarefa, descubramos algumas continuidades e outro tanto de rupturas. Mas, acima de tudo, acredito que este exercício de conhecimento histórico pode despertar para a importância que essa educação sempre teve e continua tendo em nossos dias. É possível, nesse sentido, que a investigação sobre a educação do passado possa alimentar nossa reflexão e ação sobre a educação familiar no tempo presente, não com o despropósito tantas vezes perseguido de apresentar respostas para o hoje, mas de nesse encontro do outro com o mesmo, verificarmos "a solidez e a pertinência de nossas opções e tornar nossa vontade consciente de si mesma" (Marrou, 1971, p. 5).

\section{Referências}

BANDEIRA, Júlio. Elementos de estilo: fragmentos do Brasil no caderno de viagem de Jean-Baptiste Debret. In: BANDEIRA, Júlio. Jean-Baptiste Debret caderno de viagem. Rio de Janeiro: Sextante, 2006.

BARROS, Roque Spencer Maciel de. A ilustração brasileira e a ideia de universidade. São Paulo: USP, 1986.

BASTOS, Maria Helena Câmara. A pesquisa da história da educação em revista. In: LOMBARDI, José Claudinei et. al (orgs.). Educação em debate: perspectivas, abordagens e historiografia. Campinas: Autores Associados, 2006, p. 99-128.

BECCHI, Egle. Retórica de infância. Perspectiva. Florianópolis, n. 22, 1994, p. 63-95.

BURKE, Peter. História como memória social. In: BURKE, Peter. Variedades de história cultural. Rio de Janeiro: Civilização Brasileira, 2000, p. 67-90.

CERTEAU, Michel de. A escrita da história. Rio de Janeiro: Forense, 2002.

CHARTIER, Roger. Por uma sociologia histórica das práticas culturais. In: CHARTIER, Roger. A história cultural: entre práticas e representações. Lisboa: Difel, 2002, p. 13-28.

DARNTON, Robert. História, eventos e narrativa: incidentes e cultura do cotidiano. Varia História. Belo Horizonte, n. 34, v. 21, 2005, p. 290-304.

DAVIS, Natalie Zemon. Histórias de perdão e seus narradores na França do século XVI. São Paulo: Companhia das Letras, 2001.

DONZELOT, Jacques. A polícia das famílias. Rio de Janeiro: Graal, 1980. 
DUBY, Georges. A história continua. Rio de Janeiro: Zahar, 1993.

FARGE, Arlette. Lugares para a história. Lisboa: Teorema, 1999.

FARGE, Arlette. O sabor do arquivo. São Paulo: USP, 2009.

FARIA FILHO, Luciano Mendes de. O processo de escolarização em Minas Gerais: questões teórico-metodológicas e perspectivas de análise. In: VEIGA, Cynthia Greive; FONSECA, Thais Nilvia de Lima (orgs.). História e historiografia da educação no Brasil. Belo Horizonte: Autêntica, 2008, p. 77-98.

FEBVRE, Lucien. O problema da incredulidade no século XVI: a religião de Rabelais. São Paulo: Companhia das Letras, 2009.

FEBVRE, Lucien. Viver a história. In: FEBVRE, Lucien. Combates pela história. Lisboa: Presença, 1989, p. 28-50.

GALVÃO, Ana Maria de Oliveira; LOPES, Eliane Marta Santos Teixeira. Território plural: a pesquisa em história da educação. São Paulo: Ática, 2010.

GINZBURG, Carlo. O inquisidor como antropólogo. In: GINZBURG, Carlo. A micro-história e outros ensaios. Lisboa: Difel, 1991, p. 203-214.

GINZBURG, Carlo. O queijo e os vermes. São Paulo: Companhia das Letras, 2006.

GINZBURG, Carlo. Os andarilhos do bem. São Paulo: Companhia das Letras, 2001.

GONDRA, José Gonçalves; SCHUELER, Alessandra. Educação, poder e sociedade no império brasileiro. São Paulo: Cortez, 2008.

GOUVEA, Maria Cristina Soares de. A literatura como fonte para a história da infância. In: LOPES, Alberto et al (orgs.). Para a compreensão histórica da Infância. Belo Horizonte: Autêntica, 2007, p. 19-38.

HEYWOOD, Colin. Uma história da infância: da idade média à época contemporânea no ocidente. Porto Alegre: Artmed, 2004.

LE GOFF, Jacques. Uma vida para a história: conversações com Marc Heurgon. São Paulo: Unesp, 2007.

LE ROY LADURIE, Emmanuel. Montaillou: cátaros e católicos numa aldeia francesa (1294-1324). Lisboa: Edições 70, 1975.

LE ROY LADURIE, Emmanuel. O carnaval de romans. São Paulo: Companhia das Letras, 2002.

LOPES, Eliane Marta Santos Teixeira. História da educação e literatura: algumas idéias e notas. Educação. Santa Maria, v. 30, n. 2, 2005, p. 157-176.

MARROU, Henri-Irénée. História da educação na antiguidade. São Paulo: Herder, 1971.

MELLO, Evaldo Cabral de. O fim das casas-grandes. In: ALENCASTRO, Luiz Felipe. (org.). História da vida privada no Brasil: império - a corte e a modernidade nacional. São Paulo: Companhia das Letras, 1997, p. 385-438.

MONARCHA, Carlos. História da educação (brasileira): formação do campo, tendências e vertentes investigativas. Hist. Educ. (Online), n. 21, 2007, p. 51-78.

MOREIRA, Júlio Estrella. Dicionário bibliográfico do Paraná. Curitiba: Museu Paranaense, 1957.

OZOUF, Jacques. Nous les maîtres d'école: autobiographies d'instituteurs de la Belle Époque. Paris: Juliard-Galimard, 1973. 
PERROT, Michelle. Introdução. In: PERROT, Michelle (org.). História da vida privada 4. São Paulo: Companhia das Letras, 2009, p. 7-12.

POLLOCK, Linda A. Los niños olvidados: relaciones entre padres e hijos de 1500 a 1900. México: Fondo de Cultura Econômica, 2004.

PORTELLA, Bruna et al. Redescobrindo o poder judiciário paranaense: o acervo do poder judiciário paranaense trabalhado a partir de oficinas. Curitiba, 2006, mimeo.

SHORTER, Edward. A formação da família moderna. Lisboa: Terramar, 1995.

THOMPSON, Edward Palmer. A venda de esposas. In: THOMPSON, Edward Palmer. Costumes em comum: estudos sobre a cultura popular tradicional. São Paulo: Companhia das Letras, 2009, p. 305-352.

JUAREZ JOSÉ TUCHINSKI DOS ANJOS é estudante de doutorado no Programa de Pós-Graduação em Educação da Universidade Federal do Paraná e pesquisador do Núcleo de Estudos e Pesquisas em Infância e Educação Infantil.

Endereço: Rua Carlos Ganzert, 684 - 83750-000 - Lapa - PR - Brasil.

E-mail: juarezdosanjos@yahoo.com.br.

Recebido em 12 de novembro de 2013.

Aceito em 15 de maio de 2014. 